\title{
NG2-Glia from Pallial Progenitors Produce the Largest Clonal Clusters of the Brain: Time Frame of Clonal Generation in Cortex and Olfactory Bulb
}

\author{
Jorge García-Marqués, Raúl Núñez-Llaves, and Laura López-Mascaraque \\ Instituto Cajal, CSIC, Department of Molecular, Cellular, and Developmental Neurobiology, 28002 Madrid, Spain
}

NG2-glia are the most unknown population originating in the CNS. Despite their relative abundance in the brain, fundamental questions about their function, heterogeneity, and origin remain in debate. Particularly, it is still intriguing how these cells escaped from classical in vivo clonal analyses describing other neural types. Using StarTrack labeling in mouse brains, we found that NG2-glia are produced as immense clonal clusters whose number of cells is about one order of magnitude higher than in other neural types. Unexpectedly, this number remained low during embryonic and early postnatal stages, increasing during adulthood. In addition, we also demonstrated a pallial origin of a telencephalic NG2 population, which in the olfactory bulb is derived from local progenitors. Together, our results reveal an original ontogenic process that gives rise to the NG2-glia population and expands the previously established limits of development.

Key words: clonal analysis; in utero electroporation; NG2; olfactory bulb; polydendrocytes; StarTrack

\section{Introduction}

NG2-glia or polydendrocytes are the most enigmatic population in the brain, making up $5-15 \%$ of all CNS cells (Pringle et al., 1992; Dawson et al., 2003). These cells, described three decades ago, are defined by their branched morphology and expression of both NG2-proteoglycan and $\alpha$-type platelet-derived growthfactor-receptor (PDGFR- $\alpha$ ). In addition to their well established role as oligodendrocyte precursors (Zhu et al., 2008a,b), their relative abundance and uniform distribution between gray and white matters suggest that this could be just the tip of the iceberg. Further, NG2-glia exhibit complex electrophysiological profiles (Zhou and Kimelberg, 2001; Schools et al., 2003) and receive synaptic input from neurons (Bergles et al., 2000; Lin et al., 2005). Indeed, in the barrel cortex, sensory experience regulates thalamocortical innervation of these cells, impinging in their proliferation rate (Mangin et al., 2012). Remarkably, the potential of NG2 cells as progenitors is still controversial even though it is clear their contribution to the oligodendrocyte population both during development and adulthood (Zhu et al., 2008a,b; Guo et al., 2010; Hughes et al., 2013). Likewise, NG2-glia are rapidly mobilized to replace oligodendrocytes in demyelination (Redwine and Armstrong, 1998; Zawadzka et al., 2010). However, genetic fate approaches drew different conclusions on their potential to generate astrocytes or neurons (for review, see Rich-

Received July 19, 2013; revised Dec. 11, 2013; accepted Dec. 18, 2013.

Author contributions: J.G.-M. and L.L.-M. designed research; J.G.-M., R.N.-L., and L.L.-M. performed research; J.G.-M. and L.L.-M. analyzed data; J.G.-M. and L.L.-M. wrote the paper.

This work was supported by research Grant BFU2010-15564 from the Spanish Ministry of Economy and Competitiveness.

Correspondence should be addressed to Dr Laura López-Mascaraque, Instituto Cajal (CSIC), Avenida Doctor Arce 37, 28002 Madrid, Spain. E-mail: mascaraque@cajal.csic.es.

DOI:10.1523/JNEUROSCI.3060-13.2014

Copyright $\odot 2014$ the authors $\quad 0270-6474 / 14 / 342305-09 \$ 15.00 / 0$ ardson et al., 2011; Clarke et al., 2012). The existence of a heterogeneous NG2 population could explain part of this controversy. In fact, polydendrocytes differ in the expression of molecular markers, such as glutamine synthetase (Karram et al., 2008) or myelin proteolipid protein (Mallon et al., 2002), as well as in their morphology or electrophysiological profile (Chittajallu et al., 2004; Káradóttir et al., 2008; Ge et al., 2009). Similarly, NG2-glia also vary in their proliferative response to PDGF and potential as oligodendrocyte progenitors (Viganò et al., 2013) between gray and white matter (Hill et al., 2013).

Even though this heterogeneity might have ontogenetic grounds, important aspects of NG2-glia development remain obscure. Fate mapping showed the generation of NG2-glia from dorsal and ventral domains (Malatesta et al., 2003; Kessaris et al., 2006). However, as long as specific NG2 subpopulations could emerge from different origins, analyses at population level may not be sufficient. Unfortunately, embryonic retroviral injections, which addressed the generation of all other neural types, failed to detect this abundant population. This highlights the need for novel approaches to analyze the only neural population not previously described at clonal level.

Recently, we developed the StarTrack method to trace the clonal fate of astrocytes from single progenitors (García-Marqués and López-Mascaraque, 2013). Based on the combinatorial expression of 12 fluorescent reporters under regulation of the human glial fibrillary acidic protein promoter (hGFAP), StarTrack produces progenitor-specific labels inherited by their progenies, resulting in adult labeled cell clones. Despite its specificity for astrocytes, the hGFAP promoter exhibits a weak activity on NG2glia (Matthias et al., 2003). We took advantage of such activity to trace their clonal fate, demonstrating that NG2-glia are produced as the largest clones derived from neuroepithelium. Unlike other neural types, NG2-glial clonal patches are mostly generated dur- 

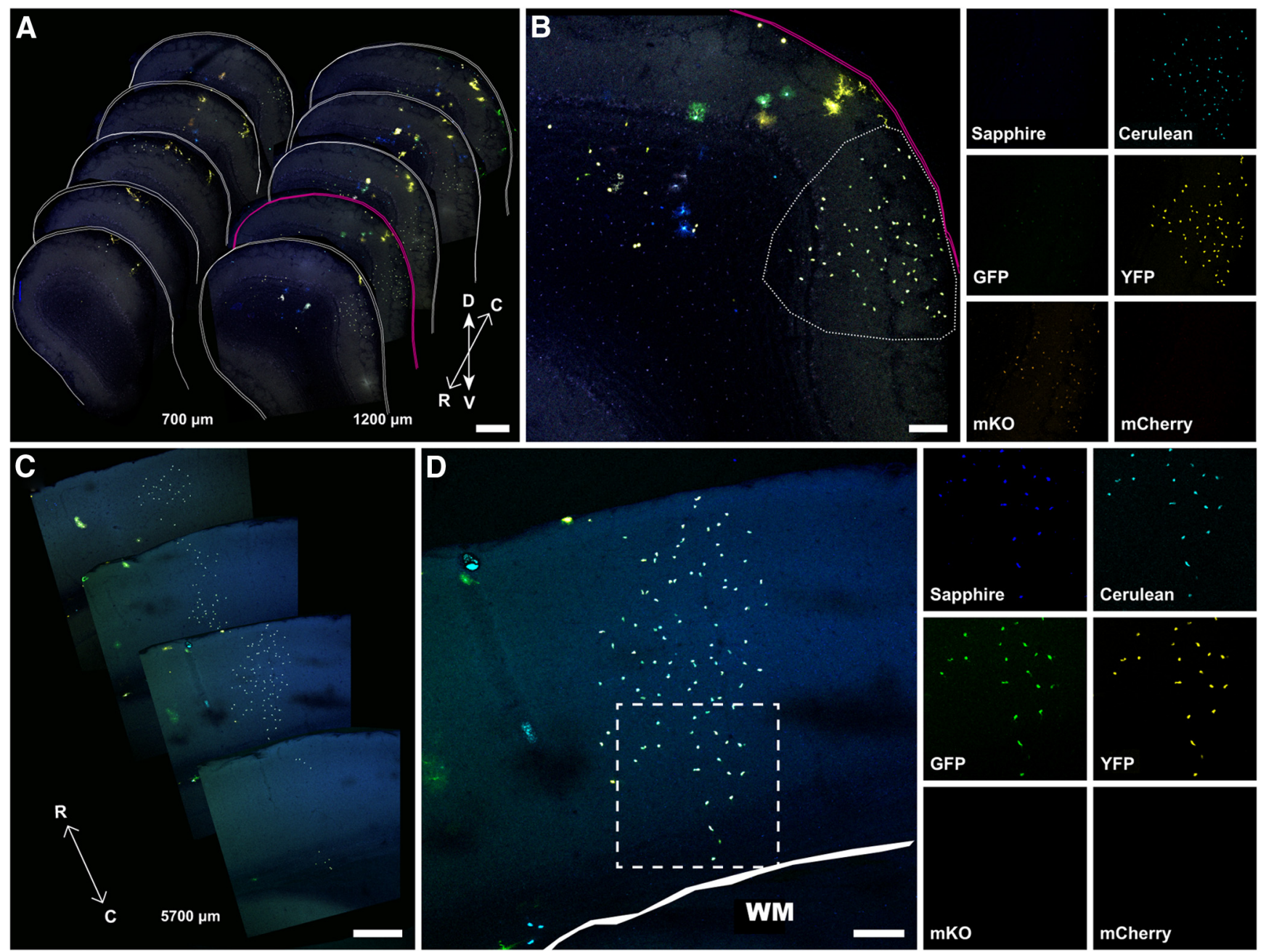

mCherry

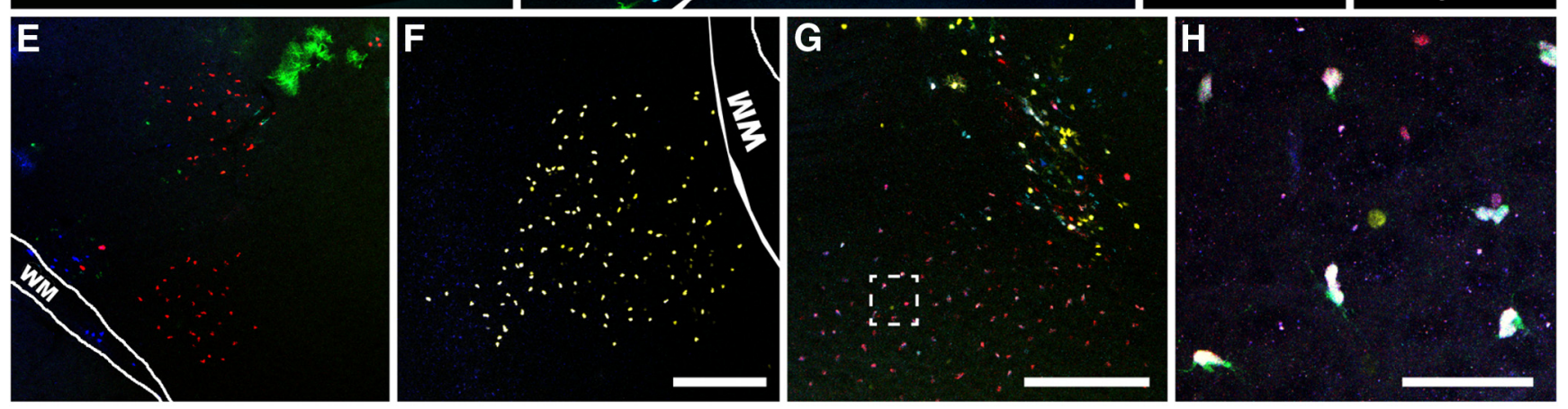

Figure 1. Adult clonal clusters after E14 in utero StarTrack coelectroporation. $A, 0 B$ serial coronal sections ( $100 \mu \mathrm{m})$ showing a clone composed of 245 cells located in outer layers. Distance from the most rostral brain point is indicated in two sections. $\boldsymbol{B}$, Detail of an $\mathrm{OB}$ clone located in the section outlined in $\boldsymbol{A}$ (pink). This clone is characterized by the nuclear expression of $\mathrm{mCerulean,}$, YFP and $\mathrm{mKO}$, as showed in individual fluorescent channels. C, Cortical clone spanned along the rostrocaudal extension. Most caudal section (100 $\mu \mathrm{m})$ is located at $5700 \mu \mathrm{m}$ from the most rostral brain point. $D$, Detail of the cortical clonal cluster showed in $\boldsymbol{C}$. This clone, arranged throughout all the cortical layers, is characterized by the expression of nuclear mT-Sapphire, mCerulean, GFP, and YFP, as revealed by individual fluorescent channels. $\boldsymbol{E}, \boldsymbol{F}$, Additional examples of cortical clones. $\boldsymbol{G}$, Additional example of an olfactory bulb clone. $\boldsymbol{H}$, Higher magnification of the clone enclosed in a dotted box in $\boldsymbol{G}$. Note this clone is characterized by a very complex label involving cytoplasmic mT-Sapphire and mCerulean, and nuclear mCherry. WM, White matter. Scales bars: $\boldsymbol{A}, \boldsymbol{C}, 300 \mu \mathrm{m} ; \boldsymbol{B}, \boldsymbol{D}, 100$ $\mu \mathrm{m} ;$ (in $\boldsymbol{F}) \boldsymbol{E}, \boldsymbol{F}, 200 \mu \mathrm{m} ; \boldsymbol{H}, 50 \mu \mathrm{m}$.

ing adulthood, representing one of the exceptional developmental processes in the adult brain.

\section{Materials and Methods}

The study was performed on C57 mice of either sex, raised at the Cajal Institute animal facility. All of the experiments were performed according to ethical regulations on the use and welfare of experimental animals of the European Union (2003/65/CE) and the Spanish Ministry of Agriculture (RD 1201/2005 and L 32/2007). These procedures were approved by the CSIC bioethical committee. Day of vaginal plug detection was defined as the first embryonic day (E0).

Plasmid vectors. StarTrack plasmids were produced as previously described (García-Marqués and López-Mascaraque, 2013). Briefly, a $2.2 \mathrm{~kb}$ fragment spanning base pairs -2163 to +47 (relative to the transcriptional start site) of the human gfap gene promoter (with the normal initiating codon converted to TTG) was chosen to direct the expression of reporters. This promoter was inserted into a PB-UbC-EGFP vector (Piggybac transposon plasmid encoding the enhanced form of the green 
Table 1. Quantitative analyses of the number of cells per clone

\begin{tabular}{|c|c|c|c|c|c|c|}
\hline Clone no. & Animal no. & Combination code & No. total cells & No. slice:cells & Location & Layers \\
\hline 1 & 1 & 000000111110 & 245 & 7:3/8:2/9:14/10:8/11:3/12:26 13:47/14:64/15:46/16:24/17:8 & $\mathrm{OB}$ & IPL to GL \\
\hline 2 & 1 & 000000110000 & 241 & $8: 4 / 9: 63 / 10: 64 / 11: 68 / 12: 40 / 13: 2$ & $\mathrm{OB}$ & GR and SEZ \\
\hline 3 & 1 & 001110100000 & 103 & $20: 8 / 21: 16 / 22: 42 / 23: 31 / 24: 6$ & $\mathrm{OB}$ & GR and SEZ \\
\hline 4 & 1 & 001110000000 & 33 & $25: 2 / 26: 14 / 27: 16 / 28: 1$ & $O B$ & GR to GL \\
\hline 5 & 2 & 000000110000 & 218 & 1:17/2:19/3:72/4:55/5:38/6:17 & $C x$ & IV to $\mathrm{VI}$ and $\mathrm{CC}$ \\
\hline 6 & 2 & 000000111100 & 123 & 3:1/4:19/5:28/6:13/7:16 8:30/9:13/10:3 & $C x$ & VI and CC \\
\hline 7 & 2 & 000000111100 & 271 & $6: 24 / 7: 82 / 8: 113 / 9: 50 / 10: 2$ & $C x$ & IV to $\mathrm{VI}$ and $\mathrm{CC}$ \\
\hline 8 & 3 & 000000111100 & 191 & $54: 31 / 55: 96 / 56: 54 / 57: 10$ & $C x$ & I to $\mathrm{VI}$ and $\mathrm{CC}$ \\
\hline 9 & 3 & 000000101100 & 125 & $14: 27 / 15: 57 / 16: 41$ & $C x$ & $\|/\|$ \\
\hline 10 & 3 & 000000110100 & 67 & $18: 3 / 19: 29 / 29: 33 / 21: 2$ & $C x$ & VI and CC \\
\hline 11 & 3 & 000000101100 & 340 & $25: 16 / 26: 107 / 27: 140 / 28: 22 / 29: 55$ & $C x$ & V to $\mathrm{VI}$ and $\mathrm{CC}$ \\
\hline 12 & 3 & 000000110100 & 89 & $25: 3 / 26: 67 / 27: 19$ & $C x$ & V to $\mathrm{VI}$ and $\mathrm{CC}$ \\
\hline 13 & 3 & 000000111100 & 187 & $30: 17 / 31: 29 / 32: 49 / 33: 27 / 34: 43 / 35: 22$ & $C x$ & II to V \\
\hline 14 & 3 & 000000110000 & 162 & $31: 9 / 32: 14 / 33: 33 / 34: 32 / 35: 19 / 36: 27 / 37: 21 / 38: 7$ & $C x$ & II to VI \\
\hline 15 & 3 & 001100110000 & 40 & $38: 15 / 39: 25$ & $C x$ & $\mathrm{VI}$ \\
\hline 16 & 3 & 000000101100 & 142 & $40: 69 / 41: 51 / 42: 20 / 43: 2$ & $C x$ & VI and CC \\
\hline 17 & 4 & 000000110000 & 57 & $2: 8 / 3: 17 / 4: 6 / 5: 22 / 6: 4$ & $\mathrm{OB}$ & GR to GL \\
\hline 18 & 4 & 001000110111 & 376 & 10:1/11:21/12:77/13:94/14:81/15:59/16:22/17:18/18:3 & $O B$ & SEZ and GR \\
\hline
\end{tabular}

Combination code indicates the qualitative expression ( $1=$ presence, $0=$ absence) of the different reporters in this order: cytoplasmic ( $m$ T-Sapphire, $\mathrm{mCerulean}$, GFP, YFP, mK0, and mCherry) and nuclear ( $\mathrm{mT}$-Sapphire, $\mathrm{mCerulean,} \mathrm{GFP}$ YFP, mKO, and mCherry). Slice number represents the rostrocaudal location of each clone beginning from the most rostral tip of the brain, considering that the slice thickness is $100 \mu \mathrm{m}$. $0 \mathrm{~B}$, Olfactory bulb; $\mathrm{C}$, cerebral cortex; IPL, internal plexiform layer; GL, glomerular layer; GR, granular layer; SEZ, subependymal zone; I-VI, cortical layers 1-6; CC, corpus callosum.

fluorescent protein (EGFP) under regulation of the ubiquitin C human gene promoter; kindly provided by Prof Bradley Wellcome Trust Sanger Institute, UK). The resulting plasmid, PB-GFAP-EGFP was subsequently used to replace the EGFP between BamHI and EcoRI with mT-Sapphire, mCerulean, yellow fluorescent protein (YFP), monomeric Kusabira Orange $(\mathrm{mKO})$, and mCherry. To generate nuclear forms of these markers, the human $h 2 b$ histone (GenBank ID X00088.1) was amplified from genomic human DNA. All plasmids were finally sequenced to ensure the accuracy of cloning.

In utero electroporation. Pregnant mice were anesthetized with isofluorane (Isova vet, Centauro), and the uterine horns were exposed by a midline incision through the skin and the abdominal wall. Uterus was transilluminated with cold light and $2 \mu \mathrm{l}$ of the plasmid mixture (2-5 $\mu \mathrm{g} / \mu \mathrm{l}$ containing $0.1 \%$ fast green) were injected using a glass micropipette into the lateral ventricles (LV) of E14 embryos. Embryos were dried to avoid current dispersion along less-resistive pathways. Then, they were placed between tweezer-type electrodes, previously wet with saline. A train of five square pulses was applied $(33 \mathrm{~V} ; 50 \mathrm{~ms}$ followed by $950 \mathrm{~ms}$ intervals) using a custom-made electroporator. The uterine horns were placed back into the abdominal cavity, filling with warm physiological saline, and the abdominal muscle and skin were closed with silk sutures. After surgery, pregnant mice received a subcutaneous injection of the antibiotic enrofloxacine ( $5 \mathrm{mg} / \mathrm{kg}$, Baytril, Bayer) and an intraperitoneal injection of the anti-inflammatory/analgesic meloxicam $(300 \mu \mathrm{g} / \mathrm{kg}$; Metacam, Boehringer Ingelheim). Embryos were allowed to survive to early postnatal (P7-P15) and adult stages (P35, P120, and P240).

Tissue staining. Early postnatal (P7 and P15) and adult mice (P35, P120, and P240) of either sex, previously electroporated at E14, were anesthetized with Equithesin ( $3 \mathrm{ml} / \mathrm{kg}$ body weight, i.p.) and perfused transcardially with $4 \%$ paraformaldehyde (PF) in $0.1 \mathrm{~m}$ phosphate buffer ( $\mathrm{PB}, \mathrm{pH} 7.2$ ) or with $2 \% \mathrm{PF}$ in $\mathrm{PB}$ containing $0.1 \mathrm{~m}$ lysine and $0.01 \mathrm{M}$ sodium metaperiodate (for NG2; McLean and Nakane, 1974). Brains were then dissected and postfixed for $2 \mathrm{~h}$ in the same solution at $4^{\circ} \mathrm{C}$ and coronal vibratome sections were obtained at 50 or $100 \mu \mathrm{m}$ depending on the experiment. Brain sections were transferred to PBS containing $0.1 \%$ Triton X-100 (PBS-T) for $5 \mathrm{~min}$. Nonspecific reactions were blocked by incubation with $2 \%$ bovine serum albumin (BSA; Sigma-Aldrich) for 30 $\mathrm{min}$ at room temperature. The sections were then incubated overnight in the following primary antibodies diluted in $1 \%$ normal goat serum in $0.1 \%$ PBS-T: rabbit anti-GFAP (1:500; Dako), rabbit anti-NG2 (1:200; Millipore), rabbit anti-PDGFR- $\alpha$ (1:200; Santa Cruz Biotechnology), rabbit anti-Olig2 (1:500; Millipore), rabbit anti-PH3 (1:500; Millipore), rabbit anti-Iba1(1:500; Wako), and mouse anti-S100- $\beta$ (1:200; Abcam).
After washing, the sections were incubated for $2 \mathrm{~h}$ with the appropriate (mice or rabbit) secondary AlexaFluor 633 (1:2000; Invitrogen).

Image settings. Fluorescent-stained sections were examined under a fluorescence microscope (Nikon, Eclipse F1) equipped with filters (Semrock) optimized for the following fluorophores: mCerulean (FF01-405/ 10), GFP (FF01-473/10), YFP (FF01-520/15), mKO (ff01-540/15), and mCherry (FF01-590/20). Then, images were obtained on a Leica TCSSP5 confocal microscope, acquiring two or three different channels simultaneously. The excitation and absorption conditions for each fluorophore were (in $\mathrm{nm}$ ) the following: mT-Sapphire (Ex: 405; Ab: 525-553), mCerulean (Ex: 458; Ab: 464-481), EGFP (Ex: 488; Ab: 496526), YFP (Ex: 514; Ab: 520-543), mKO (Ex: 514; Ab: 550-600), mCherry (Ex: 561; Ab: 601-612), and AlexaFluor 633 (Ex: 633; Ab: 649760 ). Each channel was assigned as the emission color, except for mTSapphire assigned as dark blue and AlexaFluor 633 assigned as gray or red. The projections for each channel were adjusted uniformly and overlaid using the Adobe Photoshop CS5 software.

\section{Results}

\section{Large nonastrocytic clones in the cerebral cortex and olfactory bulb}

We have recently developed the StarTrack method that allows tracking astrocyte clones from single progenitors by the generation of cell-specific multicolor labels. This method relies on the expression, under regulation of the hGFAP, of 12 fluorescent reporters inserted in the genome by the Piggybac transposon. After in utero E14 coelectroporation of the mixture, a cell-specific label is produced in those progenitors surrounding the lateral ventricles. This label is transmitted to their progeny resulting in an adult labeled cell clone. In an attempt to examine the astrocyte clonal expansion in the adult brain with StarTrack, we surprisingly discovered clones composed of hundreds of cells (up to $\approx 400$; Fig. $1 A-H)$. Quantitative analyses in adult mice (P240) showed the number of cells per clone ranged between 33 and 376 (average $=167.22 ; N=18$; Table 1 ), which arranged in large rostrocaudal extensions (up to $1.1 \mathrm{~mm}$; Table 1; Fig. 1A,C). These clones occupied several layers both in the olfactory bulb (OB; Table 1; Fig. $1 A, B$ ) and cerebral cortex (Table 1; Fig. 1C,D). Particularly, cortical clones were either mainly restricted to white matter (Fig. 2A,B) or distributed between corpus callosum and gray matter (Fig. $2 C, D$ ). In all cases, this pattern and clonal size 

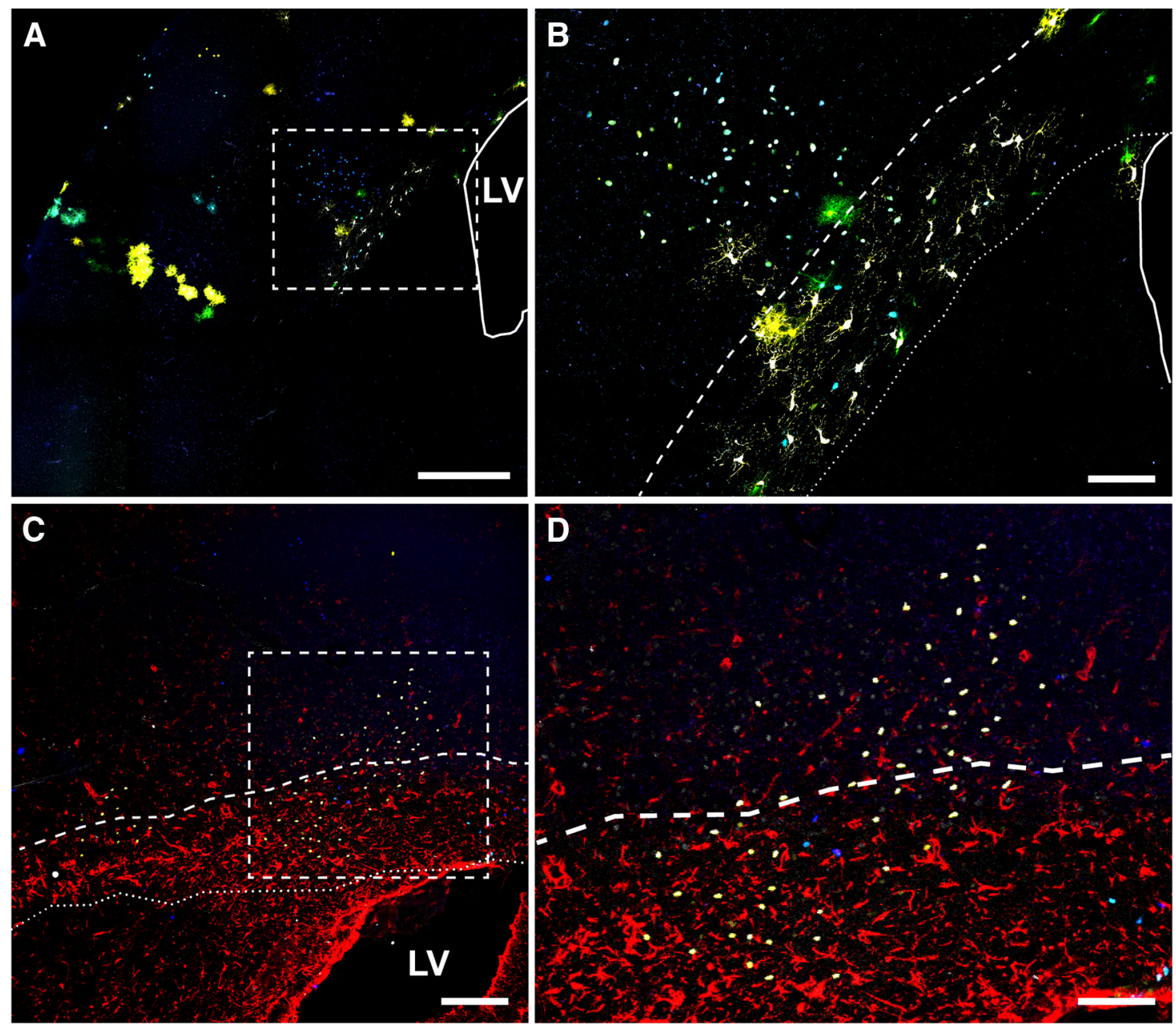

Figure 2. Clonal distribution in corpus callosum. $\boldsymbol{A}$, StarTrack-labeled clones are virtually restricted to corpus callosum (cytoplasmic labeling) or cortical layers (nuclear labeling). B, Higher magnification of the region enclosed in a dotted box in $\boldsymbol{A}$. Note the limited overlapping between both clones. $\boldsymbol{C}$, Clone distributed in both corpus callosum and cortical layers. $\boldsymbol{D}$, Higher magnification of the clone shown in $\boldsymbol{C}$. Stronger GFAP immunoreactivity (red) delimits the boundaries of the corpus callosum. Scales bars: $\boldsymbol{A}, 400 \mu \mathrm{m} ; \boldsymbol{B}, 50 \mu \mathrm{m} ; \boldsymbol{C}, 200 \mu \mathrm{m} ; \boldsymbol{D}, 100 \mu \mathrm{m}$.

was clearly different from astrocyte clones, consisting of either smaller ellipsoidal groups or narrow cell columns (Grove et al., 1993; McCarthy et al., 2001; García-Marqués and LópezMascaraque, 2013; Martín-López et al., 2013). The surprising clonal size and the different arrangement compared with astrocytes, suggested the existence of a new cell population undetected in former clonal in vivo analyses.

\section{NG2-glia identity of cortical and olfactory bulb clones}

Based on the weak activity of the hGFAP promoter in NG2-glia (Matthias et al., 2003), we performed immunohistochemistry to address whether those enormous clones were composed of polydendrocytes (Fig. 3). In all cases, these clonally related cells expressed the NG2 protein (Fig. $3 A, B$ ), being the expression pattern quite similar between the electroporated- (Fig. $3 C$ ) and the contralateral-hemispheres (Fig. 3D). This is consistent with the idea that the electroporation did not expand/modify the number of NG2 cells. Moreover, sibling cells exhibited poorly branched processes emerging from small and irregular somas (Fig. 3E), corresponding to the typical NG2-glia morphology. All of these cells were also positive for the polydendrocyte marker PDGFR- $\alpha$ (Fig. $3 F, G$ ). In an attempt to further characterize this population, we also performed immunohistochemistry for Olig2 (Fig. $3 H-J$ ) and S100- $\beta$ (Fig. $3 K-M$ ), previously detected in polydendrocytes (Hachem et al., 2005; Ligon et al., 2006). We found Olig2 expression in $95.8 \%$ of StarTrack-labeled cells (69 of 72 cells belonging to 12 different clones of P60 brains). By contrast, S100- $\beta$ was only expressed in $22.1 \%$ of these cells (21 of 95 cells in 13 different clones at P60). To discard the contribution of other glial cell types to these clones, we examined the expression of different glial markers. None of these cells expressed the protein GFAP, marker of astrocyte population (Fig. $3 N-P$ ) or the microglia marker Iba1 (Fig. 3Q-S). Because NG2-glia represent the most proliferative population in the cerebral cortex (Dawson et al., 2003), we also analyzed the presence of the proliferation marker PH3 (Fig. 3T-V). We did not observe a significant number of actively dividing NG2 cells, coincident with previous reports stating that only $\sim 1 \%$ of these cells divides in adult brain, although it is the most proliferative population (Dawson et al., 2003). In summary, these massive clonal blocks are entirely comprised by NG2-glia generated from progenitors surrounding the telencephalic ventricles at E14.

\section{Time course of NG2-glia clonal generation}

Due to their known role as oligodendrocyte progenitors, we hypothesized these clones should be generated before the onset of oligodendrogenesis (peaking P14; Sauvageot and Stiles, 2002). To determine the time frame of NG2-glia clonal generation in the 


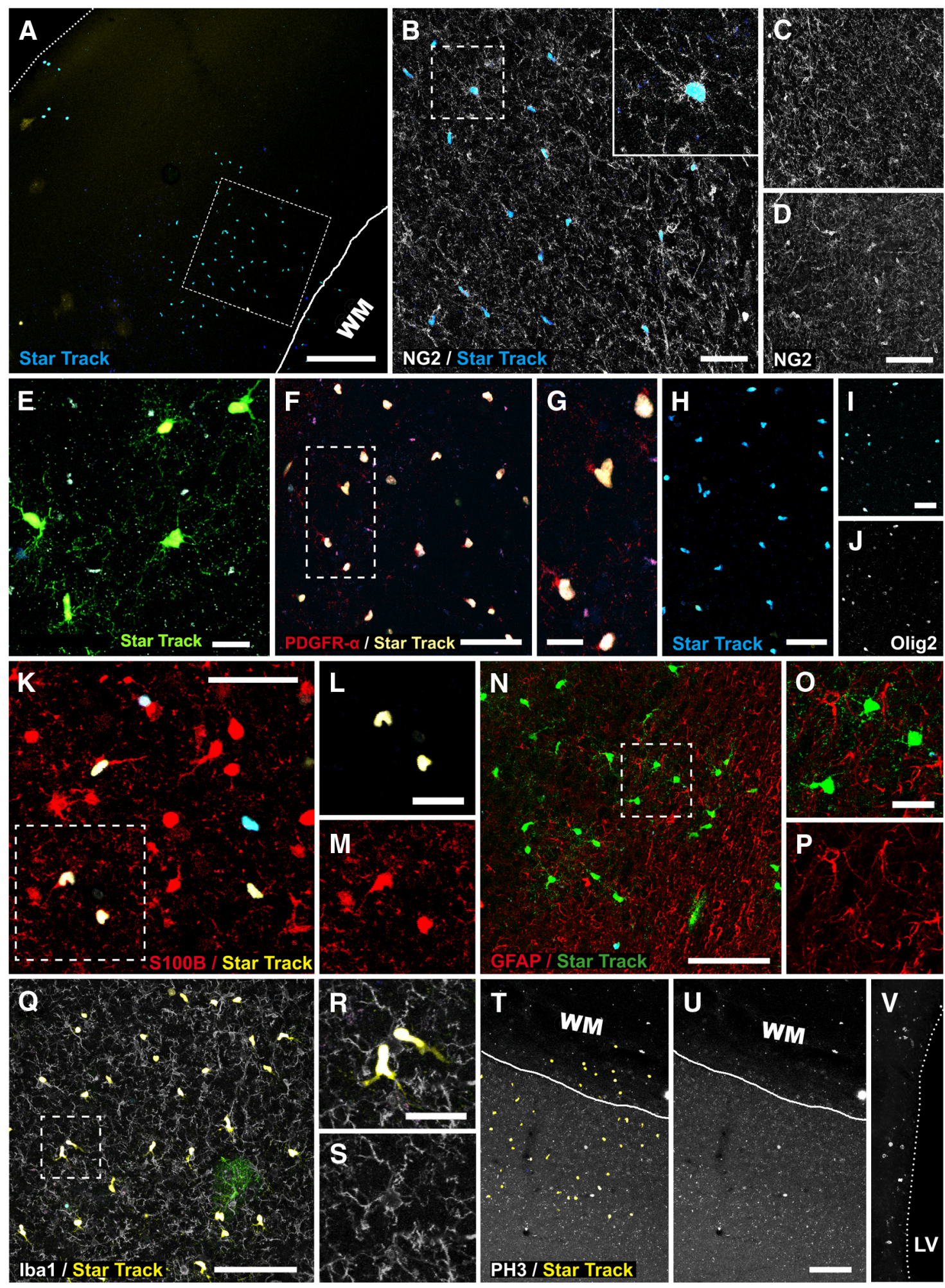

Figure 3. Immunohistochemical characterization of adult clonal cell clusters labeled by StarTrack. $A, N G 2$ expression in a cortical clone. $B$, Magnification of the region enclosed in a dotted line in $\boldsymbol{A}$, showing NG2 expression in all these sibling cells. $\boldsymbol{C}, \boldsymbol{D}$, NG2 expression pattern is similar in both the electroporated (C) and contralateral (D) hemispheres. $\boldsymbol{E}$, Morphology of sibling cells within an $O B$ cluster labeled by StarTrack. $F, G, O B$ clonal patch labeled by StarTrack is stained with the PDGFR- $\alpha$ antibody. $\boldsymbol{H}$, Cortical clonal cluster stained with the 0 lig2 antibody. $\boldsymbol{I}, \boldsymbol{J}$, Details of the clone in $\boldsymbol{H}$, showing that most of the cells $(\boldsymbol{I})$ expressed Olig2 $(\boldsymbol{J}) . \boldsymbol{K}, \mathbf{S} 100-\beta$ labeling is restricted to few sibling cells within a clone. $\boldsymbol{L}, \boldsymbol{M}$, Detail of the region

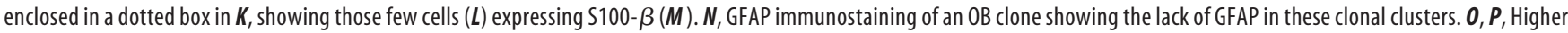
magnification of sibling cells $(\mathbf{O})$ enclosed in a dotted box in N and expression of GFAP $(\boldsymbol{P})$. $\mathbf{Q}$, Lack of expression of the microglial marker Iba1 in these clones. $\boldsymbol{R}, \boldsymbol{S}$, Higher magnification of region enclosed in a dotted box in $\mathbf{Q}$, showing an example of those cells $(\boldsymbol{R})$ without any expression of IBA1 (S). $\boldsymbol{T}, \boldsymbol{U}$, Most of the analyzed sibling cells $(\boldsymbol{T})$ showed an absence of PH3 immunostaining $(\boldsymbol{U})$. $\boldsymbol{V}$, PH3-positive control in the same section showing some dividing cells close to the lateral ventricle. WM, White matter. Scales bars: $\boldsymbol{A}, 200 \mu \mathrm{m} ; \boldsymbol{B}, \boldsymbol{E}-\boldsymbol{H}, \boldsymbol{I}$ (for $\boldsymbol{I}$, $\boldsymbol{J}), \boldsymbol{K}, 50 \mu \mathrm{m} ; \boldsymbol{U}$ (for $\boldsymbol{C}, \boldsymbol{D}, \boldsymbol{N}, \boldsymbol{Q}, \boldsymbol{T}-\boldsymbol{V}$ ) , $100 \mu \mathrm{m} ; \boldsymbol{L}$ (for $\boldsymbol{L}, \boldsymbol{M}$ ), $\boldsymbol{O}$ (for $\mathbf{O}, \boldsymbol{P}$ ), $\boldsymbol{R}$ (for $\boldsymbol{R}, \boldsymbol{S}$ ), $25 \mu \mathrm{m}$. 

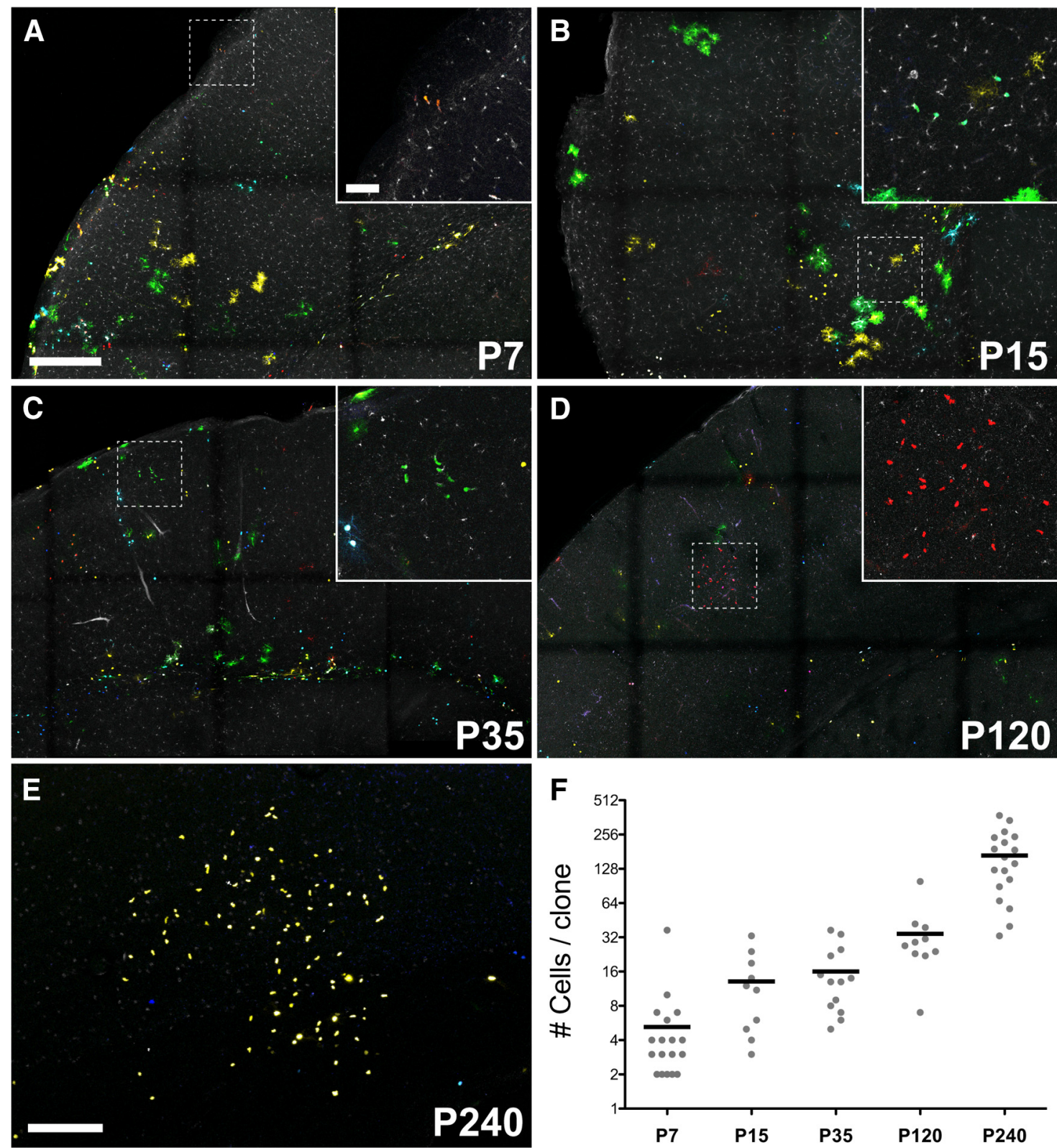

Figure 4. Time frame of clonal NG2-glia generation. Coronal cortical slices at P7 (A), P15 (B), P35 (C), P120 (D), and P240 (E), immunostained against PDGFR- $\alpha$. Clones in $\boldsymbol{A}-\mathbf{C}$ exhibit StarTrack cytoplasmic labeling in contrast to the nuclear staining of clones in $\boldsymbol{D}$ and $\boldsymbol{E}$. $\boldsymbol{F}$, Graph showing the quantitative analysis of the number of cells per clone for each developmental stage. Each point shows a clone and horizontal lines represent the average of these observations. Note those values in the $y$-axis are expressed in a logarithmic scale (Log2). Scale bars: (in $\boldsymbol{A}) \boldsymbol{A}-\boldsymbol{D}, 300 \mu \mathrm{m}$. Magnifications: (in $A) A-D, 50 \mu \mathrm{m} ; \boldsymbol{E}, 150 \mu \mathrm{m}$.

cerebral cortex, we performed additional series of electroporations at E14, analyzing clonal composition at P7, P15, P35, and P120 (Fig. 4). A comprehensive examination of NG2-glia clones at P7 (Fig. $4 A, F$ ) revealed the presence of small clones composed of a limited number of cells (mean $=5.2 ; N=24$; Fig. $4 F$ ). Despite their similarity to adult stages, their processes were characterized by less branching. These cells exhibited a singular morphology clearly different from astrocytes in size, branching, and soma shape (Fig. 4A). In addition, we detected strong immunoreactivity for PDGFR- $\alpha$, which was absent in astrocytes. This morphology was similar during the following weeks, whereas the number of cells per clone increased at P15 (mean $=13.1 ; N=10$; Fig. $4 B, F$ ) and P35 (mean $=16 ; N=13$; Fig. $4 C, F$ ). Large NG2 clones were already obvious at P120 (mean $=34.3 ; N=10$ ), although the number of cells per clone was still very low com- pared with P240 (mean $=167.2 ; N=18 ;$ Fig. $4 F)$. This marked difference in the number of cells per clone between P120 and P240, suggested an exponential component in their growth curve. It is also noteworthy the intensity decay of PDGFR- $\alpha$ immunostaining with age. Together, these findings reveal that the bulk of NG2-glia clones emerged during adulthood, after most developmental processes have concluded.

\section{Clonal dispersion and migratory routes of NG2 cells}

The relationship between the developmental origin and final destination of NG2 cells remains unknown at single-cell level, particularly those destined to important brain areas as the OB. We analyzed the correlation between the electroporated ventricular region and the final destination of these clonal clusters (Fig. 5). In the $\mathrm{OB}$, only those electroporations targeting the olfactory ven- 


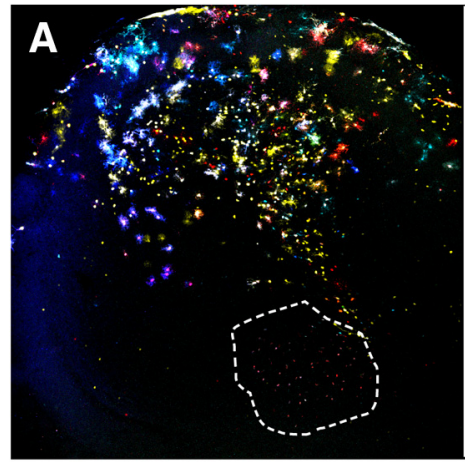

\section{Olfactory Bulb}

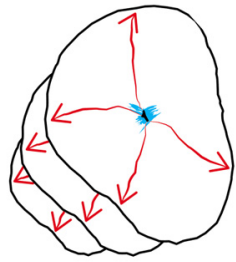

\section{B}

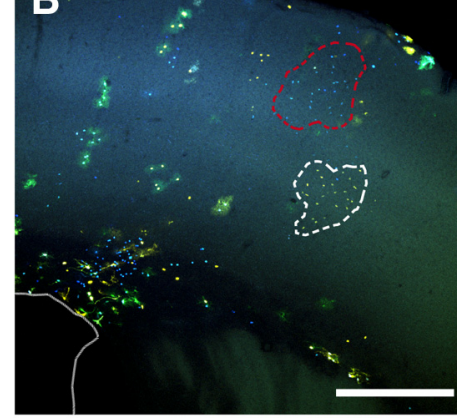

Cerebral Cortex

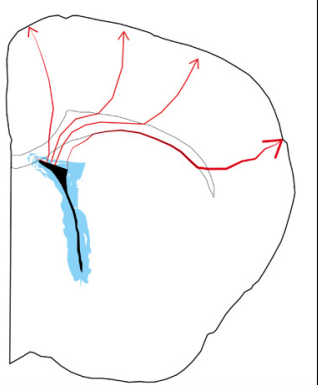

Figure 5. Clonal dispersion after StarTrack electroporation at $E 14$, showing migratory routes of NG2 cells in both adult $O B(\boldsymbol{A})$ and cerebral cortex $(\boldsymbol{B})$. $\boldsymbol{A}$, Electroporations restricted to the olfactory ventricular area gave rise to astrocytes and NG2 cells (encircled), which dispersed following radial directions (fan shape). $\boldsymbol{B}$, Those electroporations targeting the dorsal part of lateral ventricles produced astrocytes and NG2 cells (encircled) dispersed following the radial glia processes. In the most rostral parts, these cells followed curved routes projected in the rostral direction. In the rest of the dorsal extension, astrocytes and NG2 cells followed sinusoidal mediolateral pathways, from the ventricular corner to lateral cortical areas. This sinusoidal pathway was less evident in those electroporations targeting the dorsomedial ventricular region. Scale bars: $\boldsymbol{A}, \boldsymbol{B}, 400 \mu \mathrm{m}$.

tricle produced NG2 cells (Fig. 5A). By contrast, none of these $\mathrm{NG} 2$ cells were observed in the $\mathrm{OB}$ when the electroporation was restricted to the ventricular zone of the lateral ventricles. This demonstrated that at least one NG2-glia subpopulation in the OB derives from local progenitors surrounding the olfactory ventricle. Similarly, electroporations in the dorsal/dorsolateral parts of the lateral ventricle produced NG2 clones along the entire mediolateral and rostrocaudal cortical extension (Fig. $5 B$ ). Both the absence of labeling in the ventral part of the ventricular wall and the lack of astrocytes in ventral regions supported that these regions were not accidentally targeted. Thus, clonal dispersion of pallial NG2-glia followed a pattern resembling the astrocyte development, in close relationship with the course of radial glia processes (Marshall et al., 2003).

\section{Discussion}

We revealed the generation of immense clonal patches comprised by up to $\approx 400$ NG2 cells arranged as colonies in both the neocortex and OB. The bulk of these massive clones emerged after 4 months. The relationship between the cell dispersion pattern and the electroporated regions revealed an origin from E14 pallial progenitors, whose progeny reached its destination following the radial glia course.

The retrovirus advent as a tool for in vivo clonal analysis opened the most prolific period describing how neuronal/astrocytic/oligodendrocytic lineages originated from single embryonic progenitors (Price and Thurlow, 1988; Walsh and Cepko, 1988,
1992; Luskin et al., 1993; McCarthy et al., 2001). At the present time, although many aspects about these processes remain uncertain, we have a rough idea. By contrast, it is still an enigma why these studies failed to describe glial populations as NG2-glia, pial astrocytes (García-Marqués and López-Mascaraque, 2013), or the entire OB glial population (Reid et al., 1999). Although epigenetic silencing might contribute to the lack of labeling (McCarthy et al., 2001), these retroviral injections restricted to the LVs, only labeling dividing cells in direct contact with CSF. Nevertheless, quiescent NG2-progenitors or those without any CSF contact would be ignored. This may explain why it was possible to target NG2 cells by direct retroviral injections into postnatal SVZ (Levison et al., 1999). In any case, StarTrack overcame these drawbacks, labeling the largest clones derived from the neural tube. This was due to the artifactual activity of the hGFAP promoter in NG2-glia (Matthias et al., 2003), as these cells do not transcribe the mRNA for GFAP (Ye et al., 2003). A thorough analysis confirmed their identity as NG2-glia, characterized by the expression of markers such as NG2, PDGFR- $\alpha$, and Olig2. Typically, these clones distributed along multiple layers in the $\mathrm{OB}$ and cortex. Still, a low number of clones are mainly restricted to corpus callosum, whose significance is unclear. It might be casuistic or be behind of particular characteristics of the callosal population, such as their electrophysiological profile (Chittajallu et al., 2004), their special potential as oligodendrocyte progenitors (Viganò et al., 2013), or a greater proliferative response to PDGF signaling (Hill et al., 2013).

This study demonstrated that NG2-glia are produced as the largest clones derived from the neural tube. Our results differ from observation of NG2-glia clones with an average of 9.5 cells (at P90) after retroviral injections in perinatal SVZ, although that study did not examine older brains (Levison et al., 1999). Such discrepancy probably arises from different animal models/stages/ regions targeted in each case. Indeed, these authors also reported astrocyte clones composed of few cells compared with embryonic retroviral labeling (McCarthy et al., 2001). In addition to this work, NG2-clonal generation was only described by recombinatorial fate mapping, reporting small NG2 clones (up to 9 cells) $60 \mathrm{~d}$ after labeling induction at P2 (Zhu et al., 2011). This number is also notably lower than our data at P35 (Fig. 4C,F), although this must be taken with caution since that study discarded those clones containing $>20$ cells. Therefore, we conclude that NG2glia are produced as much larger clones than previously thought, in contrast to other neural types. Whereas neuronal clones consist of up to $\approx 10$ cells and astrocytes/oligodendrocytes form clones up to $\approx 50$ cells (Price and Thurlow, 1988; McCarthy et al., 2001), NG2 clones contained up to $\approx 400$ cells. Because these studies analyzed clones before the first month of age, it could be argued that other neural types also increase their clonal size after P30. Obviously, this is not the case of neurons because adult neurogenesis only persists within the hippocampus and $\mathrm{OB}$ (Ming and Song, 2011). We neither observed an increment of the astrocytic clonal size in agreement with previous descriptions (Levison et al., 1999). However, rat oligodendrocytes increased 3.5-fold between 1 and 5 months (Ling and Leblond, 1973; McCarthy and Leblond, 1988), suggesting that they might also form larger clones in older animals.

Electroporations in dorsoventricular regions correlated with NG2-clonal labeling in the cortex, whereas those performed in the olfactory ventricle correlated with $\mathrm{OB}$ labeling. Such information is extremely relevant because it demonstrates that at least a telencephalic NG2-glia subpopulation derives from E14 pallial progenitors. So far, the origin of NG2-glia remains unclear. Be- 
cause of their role as oligodendrocyte progenitors, it is assumed that polydendrocytes emerge from the same domains. This view is supported by fate mapping reporting NG2-glia as one of the main populations originated from ventral radial glia (Malatesta et al., 2003). However, this may be an erroneous generalization considering that embryonic and adult oligodendrocyte progenitors could be different populations. Indeed, it has been reported the generation of oligodendrocyte/oligodendrocyte-progenitors from a pallial wave about birth (Kessaris et al., 2006), which fits perfectly with our pallial-restricted electroporations labeling NG2-glia. Further, there is not description on the generation of NG2 population in the OB. Our data evidenced that only those electroporations targeting the olfactory ventricular/subventricular zones allowed to label OB polydendrocytes, in contrast to LV electroporations. Nevertheless, it could be argued that the loss of adult ventricular labeling led us to ignore the ventral contribution, even though in that case we should observe astrocytes in ventral regions (Marshall et al., 2003). Likewise, it could be possible that pallial cells labeled at E14 were actually derived from the subpallium at earlier stages, being electroporated in their migration to the dorsal pallium. However, this would imply extensive cell migrations from proliferative subpallial to proliferative pallial areas (electroporated areas), not previously observed (GarcíaMoreno et al., 2008). Moreover, the first oligodendrocyte progenitors originated in ventral regions arrived to pallium after E14 (Kessaris et al., 2006). Therefore, we conclude that at least a significant NG2-glia subpopulation derives from proliferative pallial regions. Thus, NG2 cells derived from pallial progenitors in the ventricular/subventricular regions migrate following the course of radial glia processes to reach their final destination. Once there, these progenitors proliferate to produce the largest clones derived from neural tube. This developmental process is identical to astrocytes that proliferate locally throughout symmetrical divisions to rapidly expand their cell number (Ge et al., 2012; García-Marqués and López-Mascaraque, 2013). This symmetrical proliferation, in which each cell produces two cells with a certain proliferative potential, would also explain the exponential NG2-clonal growth (Fig. 4F).

Our findings demonstrated an unanticipated progression of clonal size during adulthood, characterized by an exponential growth where the majority of cells emerged between 4 and 8 months of life. This is consistent with the maintenance of a proliferative population in adulthood (Dawson et al., 2003). In addition, SVZ-derived NG2 clones also doubled in size between 1 and 3 months, despite the quantitative difference in size mentioned above (Levison et al., 1999). This is also consistent with the cell-cycle time lengthening in older animals (Psachoulia et al., 2009) because the time to double the initial population is shorter in P7-P15 compared with P120-P240 (Fig. 4F). Then, could it be possible that clonal size increment persists during the whole life? Dawson et al. (2003) reported high proliferation even at 11 months old, which makes this hypothesis possible. Future evidence in aging brains should clarify this point. Regardless, this clonal remodeling is essential for our conception of brain development, as it crosses the boundaries of what we consider an adult brain.

NG2-glia are the most proliferative population in the adult brain (Dawson et al., 2003), although its number remains stable between young and old animals (Sim et al., 2002; Rivers et al., 2008; Hughes et al., 2013; Ming et al., 2013). Even assuming a net increment in NG2-glia, this should be low and nonobvious for previous studies. Because NG2-glia death is uncommon in adult brain (Dawson et al., 2003), the fate of this proliferation is un- clear. A significant oligodendrocyte generation in adult brain, throughout direct differentiation of NG2-glia (Zhu et al., 2011; Hughes et al., 2013), suggests this proliferation is a homeostatic response to replace these NG2 cells (Simon et al., 2011; Hughes et al., 2013). Furthermore, assuming a stable number between young and old animals, the outstanding cell increment in our NG2 clones should be concurrent with a size reduction of other nonlabeled NG2 clones. This supports the idea of clonal NG2-glia specialization with some clones increasing their size at the expense of other clones committed to oligodendrocyte production throughout direct differentiation (in the absence of a significant NG2-glia death). Accordingly, an important part of NG2 clones does not generate oligodendrocytes (Levison et al., 1999; Zhu et al., 2011). Unfortunately, the hGFAP promoter is not active in oligodendrocytes impeding to follow this differentiation process. Intriguingly, the possible existence of clones that never differentiate into oligodendrocytes raises many questions. What is their functional significance in the brain? How are they related to aging? Is this specialization a consequence of multiple origins for each type? According to the oligodendrocyte ventral origin, it is plausible that pallial-derived NG2 clones increase their size at the expense of the direct differentiation in oligodendrocytes of ventralderived NG2 clones. Despite the proposed functional equivalence of ventral and dorsal waves (Kessaris et al., 2006), the specialization hypothesis would explain why the majority of dorsal SVZderived NG2 cells never differentiated into oligodendrocytes (Levison et al., 1999).

To date, NG2-glia development has been mostly described by prospective methods assuming expression of genetic markers in progenitors (Zhu et al., 2008a,b). Along with other drawbacks (Richardson et al., 2011), this claims for different views based on retrospective approaches. Here, StarTrack evidences such necessity revealing critical aspects of this enigmatic cell population that are exclusively noticeable by clonal analysis, such as the important remodeling process of this population during adulthood. These surprising data will contribute to the mystery of these cells, providing the missing piece in the clonal puzzle of the brain.

\section{References}

Bergles DE, Roberts JD, Somogyi P, Jahr CE (2000) Glutamatergic synapses on oligodendrocyte precursor cells in the hippocampus. Nature 405:187191. CrossRef Medline

Chittajallu R, Aguirre A, Gallo V (2004) NG2-positive cells in the mouse white and grey matter display distinct physiological properties. J Physiol 561:109-122. CrossRef Medline

Clarke LE, Young KM, Hamilton NB, Li H, Richardson WD, Attwell D (2012) Properties and fate of oligodendrocyte progenitor cells in the corpus callosum, motor cortex, and piriform cortex of the mouse. J Neurosci 32:8173-8185. CrossRef Medline

Dawson MR, Polito A, Levine JM, Reynolds R (2003) NG2-expressing glial progenitor cells: an abundant and widespread population of cycling cells in the adult rat CNS. Mol Cell Neurosci 24:476-488. CrossRef Medline

García-Marqués J, López-Mascaraque L (2013) Clonal identity determines astrocyte cortical heterogeneity. Cereb Cortex 23:1463-1472. CrossRef Medline

García-Moreno F, López-Mascaraque L, de Carlos JA (2008) Early telencephalic migration topographically converging in the olfactory cortex. Cereb Cortex 18:1239-1252. CrossRef Medline

Ge WP, Zhou W, Luo Q, Jan LY, Jan YN (2009) Dividing glial cells maintain differentiated properties including complex morphology and functional synapses. Proc Natl Acad Sci U S A 106:328-333. CrossRef Medline

Ge WP, Miyawaki A, Gage FH, Jan YN, Jan LY (2012) Local generation of glia is a major astrocyte source in postnatal cortex. Nature 484:376-380. CrossRef Medline

Grove EA, Williams BP, Li DQ, Hajihosseini M, Friedrich A, Price J (1993) Multiple restricted lineages in the embryonic rat cerebral cortex. Development 117:553-561. Medline 
Guo F, Maeda Y, Ma J, Xu J, Horiuchi M, Miers L, Vaccarino F, Pleasure D (2010) Pyramidal neurons are generated from oligodendroglial progenitor cells in adult piriform cortex. J Neurosci 30:12036-12049. CrossRef Medline

Hachem S, Aguirre A, Vives V, Marks A, Gallo V, Legraverend C (2005) Spatial and temporal expression of S100B in cells of oligodendrocyte lineage. Glia 51:81-97. CrossRef Medline

Hill RA, Patel KD, Medved J, Reiss AM, Nishiyama A (2013) NG2 cells in white matter but not gray matter proliferate in response to PDGF. J Neurosci 33:14558-14566. CrossRef Medline

Hughes EG, Kang SH, Fukaya M, Bergles DE (2013) Oligodendrocyte progenitors balance growth with self-repulsion to achieve homeostasis in the adult brain. Nat Neurosci 16:668-676. CrossRef Medline

Káradóttir R, Hamilton NB, Bakiri Y, Attwell D (2008) Spiking and nonspiking classes of oligodendrocyte precursor glia in CNS white matter. Nat Neurosci 11:450-456. CrossRef Medline

Karram K, Goebbels S, Schwab M, Jennissen K, Seifert G, Steinhäuser C, Nave KA, Trotter J (2008) NG2-expressing cells in the nervous system revealed by the NG2-EYFP-knockin mouse. Genesis 46:743-757. CrossRef Medline

Kessaris N, Fogarty M, Iannarelli P, Grist M, Wegner M, Richardson WD (2006) Competing waves of oligodendrocytes in the forebrain and postnatal elimination of an embryonic lineage. Nat Neurosci 9:173-179. CrossRef Medline

Levison SW, Young GM, Goldman JE (1999) Cycling cells in the adult rat neocortex preferentially generate oligodendroglia. J Neurosci Res 57:435446. CrossRef Medline

Ligon KL, Kesari S, Kitada M, Sun T, Arnett HA, Alberta JA, Anderson DJ, Stiles CD, Rowitch DH (2006) Development of NG2 neural progenitor cells requires Olig gene function. Proc Natl Acad Sci U S A 103:78537858. CrossRef Medline

Lin SC, Huck JH, Roberts JD, Macklin WB, Somogyi P, Bergles DE (2005) Climbing fiber innervation of NG2-expressing glia in the mammalian cerebellum. Neuron 46:773-785. CrossRef Medline

Ling EA, Leblond CP (1973) Investigation of glial cells in semithin sections. II. Variation with age in the numbers of the various glial cell types in rat cortex and corpus callosum. J Comp Neurol 149:73-81. CrossRef Medline

Luskin MB, Parnavelas JG, Barfield JA (1993) Neurons, astrocytes, and oligodendrocytes of the rat cerebral cortex originate from separate progenitor cells: an ultrastructural analysis of clonally related cells. J Neurosci 13: 1730-1750. Medline

Malatesta P, Hack MA, Hartfuss E, Kettenmann H, Klinkert W, Kirchhoff F, Götz M (2003) Neuronal or glial progeny: regional differences in radial glia fate. Neuron 37:751-764. CrossRef Medline

Mallon BS, Shick HE, Kidd GJ, Macklin WB (2002) Proteolipid promoter activity distinguishes two populations of NG2-positive cells throughout neonatal cortical development. J Neurosci 22:876-885. Medline

Mangin JM, Li P, Scafidi J, Gallo V (2012) Experience-dependent regulation of NG2 progenitors in the developing barrel cortex. Nat Neurosci 15: 1192-1194. CrossRef Medline

Marshall CA, Suzuki SO, Goldman JE (2003) Gliogenic and neurogenic progenitors of the subventricular zone: who are they, where did they come from, and where are they going? Glia 43:52-61. CrossRef Medline

Martín-López E, García-Marques J, Núñez-Llaves R, López-Mascaraque L (2013) Clonal astrocytic response to cortical injury. PLoS ONE 8:e74039. CrossRef Medline

Matthias K, Kirchhoff F, Seifert G, Hüttmann K, Matyash M, Kettenmann H, Steinhäuser C (2003) Segregated expression of AMPA-type glutamate receptors and glutamate transporters defines distinct astrocyte populations in the mouse hippocampus. J Neurosci 23:1750-1758. Medline

McCarthy GF, Leblond CP (1988) Radioautographic evidence for slow astrocyte turnover and modest oligodendrocyte production in the corpus callosum of adult mice infused with $3 \mathrm{H}$-thymidine. J Comp Neurol 271: 589-603. CrossRef Medline

McCarthy M, Turnbull DH, Walsh CA, Fishell G (2001) Telencephalic neural progenitors appear to be restricted to regional and glial fates before the onset of neurogenesis. J Neurosci 21:6772-6781. Medline

McLean IW, Nakane PK (1974) Periodate-lysine-paraformaldehyde fixative: a new fixation for immunoelectron microscopy. J Histochem Cytochem 22:1077-1083. CrossRef Medline
Ming GL, Song H (2011) Adult neurogenesis in the mammalian brain: significant answers and significant questions. Neuron 70:687-702. CrossRef Medline

Ming X, Chew LJ, Gallo V (2013) Transgenic overexpression of Sox17 promotes oligodendrocyte development and attenuates demyelination. J Neurosci 33:12528-12542. CrossRef Medline

Price J, Thurlow L (1988) Cell lineage in the rat cerebral cortex: a study using retroviral-mediated gene transfer. Development 104:473-482. Medline

Pringle NP, Mudhar HS, Collarini EJ, Richardson WD (1992) PDGF receptors in the rat CNS: during late neurogenesis, PDGF alpha-receptor expression seems to be restricted to glial cells of the oligodendrocyte lineage. Development 115:535-551. Medline

Psachoulia K, Jamen F, Young KM, Richardson WD (2009) Cell cycle dynamics of NG2 cells in the postnatal and ageing brain. Neuron Glia Biol 5:57-67. CrossRef Medline

Redwine JM, Armstrong RC (1998) In vivo proliferation of oligodendrocyte progenitors expressing PDGFalphaR during early remyelination. J Neurobiol 37:413-428. CrossRef Medline

Reid CB, Liang I, Walsh CA (1999) Clonal mixing, clonal restriction, and specification of cell types in the developing rat olfactory bulb. J Comp Neurol 403:106-118. CrossRef Medline

Richardson WD, Young KM, Tripathi RB, McKenzie I (2011) NG2-glia as multipotent neural stem cells: fact or fantasy? Neuron 70:661-673. CrossRef Medline

Rivers LE, Young KM, Rizzi M, Jamen F, Psachoulia K, Wade A, Kessaris N, Richardson WD (2008) PDGFRA/NG2-positive glia generate myelinating oligodendrocytes and piriform projection neurons in adult mice. Nat Neurosci 11:1392-1401. CrossRef Medline

Sauvageot CM, Stiles CD (2002) Molecular mechanisms controlling cortical gliogenesis. Curr Opin Neurobiol 12:244-249. CrossRef Medline

Schools GP, Zhou M, Kimelberg HK (2003) Electrophysiologically "complex" glial cells freshly isolated from the hippocampus are immunopositive for the chondroitin sulfate proteoglycan NG2. J Neurosci Res 73:765-777. CrossRef Medline

Sim FJ, Zhao C, Penderis J, Franklin RJ (2002) The age-related decrease in CNS remyelination efficiency is attributable to an impairment of both oligodendrocyte progenitor recruitment and differentiation. J Neurosci 22:2451-2459. Medline

Simon C, Götz M, Dimou L (2011) Progenitors in the adult cerebral cortex: cell cycle properties and regulation by physiological stimuli and injury. Glia 59:869-881. CrossRef Medline

Viganò F, Möbius W, Götz M, Dimou L (2013) Transplantation reveals regional differences in oligodendrocyte differentiation in the adult brain. Nat Neurosci 16:1370-1372. CrossRef Medline

Walsh C, Cepko CL (1988) Clonally related cortical cells show several migration patterns. Science 241:1342-1345. CrossRef Medline

Walsh C, Cepko CL (1992) Widespread dispersion of neuronal clones across functional regions of the cerebral cortex. Science 255:434-440. CrossRef Medline

Ye P, Bagnell R, D'Ercole AJ (2003) Mouse NG2 + oligodendrocyte precursors express mRNA for proteolipid protein but not its DM-20 variant: a study of laser microdissection-captured NG2 + cells. J Neurosci 23:44014405. Medline

Zawadzka M, Rivers LE, Fancy SP, Zhao C, Tripathi R, Jamen F, Young K, Goncharevich A, Pohl H, Rizzi M, Rowitch DH, Kessaris N, Suter U, Richardson WD, Franklin RJ (2010) CNS-resident glial progenitor/ stem cells produce Schwann cells as well as oligodendrocytes during repair of CNS demyelination. Cell Stem Cell 6:578-590. CrossRef Medline

Zhou M, Kimelberg HK (2001) Freshly isolated hippocampal CA1 astrocytes comprise two populations differing in glutamate transporter and AMPA receptor expression. J Neurosci 21:7901-7908. Medline

Zhu X, Bergles DE, Nishiyama A (2008a) NG2 cells generate both oligodendrocytes and gray matter astrocytes. Development 135:145-157. CrossRef Medline

Zhu X, Hill RA, Nishiyama A (2008b) NG2 cells generate oligodendrocytes and gray matter astrocytes in the spinal cord. Neuron Glia Biol 4:19-26. CrossRef Medline

Zhu X, Hill RA, Dietrich D, Komitova M, Suzuki R, Nishiyama A (2011) Age-dependent fate and lineage restriction of single NG2 cells. Development 138:745-753. CrossRef Medline 